\title{
KHẢO SÁT GIÁ TRI ALPHA-FETOPROTEIN HUYẾT THANH Ở BÊ̂NH NHÂN XƠ GAN Có UNG THƯ BIỂU MÔ TẾ BÀO GAN
}

\section{TÓM TẮT}

Mục tiêu: Khảo sát giá trị alpha-fetoprotein (AFP) huyết thanh ở bệnh nhân xơ gan có và không có ung thư biểu mô tế bào gan (HCC). Đối tượng và phương pháp: Nghiên cứu cắt ngang mổ tả 75 trường hợp xơ gan tại Bệnh viện Đại Học Y Dược Thành Phố Hồ Chí Minh chúng tôi ghi nhận có 46 trường hợp HCC và 29 trường hợp không có HCC từ tháng 09/2020 đến tháng 1/2021. Kết quả: Tuổi trung bình $61,9 \pm 10,9$, tỉ lệ nam/nữ là $1,68 / 1$. AUROC của nồng độ AFP để chẩn đoán HCC ở bệnh nhân xơ gan là tốt với $A U C=0,8291, p=0,047<0,05$. Ngưỡng cắt AFP $\geq 10,9 \mathrm{ng} / \mathrm{ml}$ có giá trị cao nhất để chẩn đoán HCC ở bệnh nhân xơ gan với độ nhạy là $80,43 \%$ và độ đặc hiệu là $75,86 \%$. Kết luận: Nông độ AFP huyểt thanh là xét nghiệm đơn giản, với ngưỡng cắt $A F P \geq 10,9 \mathrm{ng} / \mathrm{ml}$, có độ nhạy và độ đặc hiêuu cao trong tầm soát biến chứng HCC ở bệnh nhẩn xơ gan.

Tư khóa: AFP, HCC, xơ gan

\section{SUMMARY}

INVESTIGATION ALPHA-FETOPROTEIN IN CIRRHOTIC PATIENTS WITH HEPATOCELLULAR CARCINOMA

Objective: To investigate alpha-fetoprotein (AFP) level in cirrhotic patients with and without hepatocellular carcinoma (HCC). Method: A crosssectional study describing 75 cases of patients with cirrhosis was conducted at the University Medical Center. We recorded 46 cases of HCC and 29 cases without HCC from September 2020 to January 2021. Results: The mean age of patients was $61,9 \pm 10,9$, the ratio male/female was $1,68 / 1$. The AUROC of AFP levels for the diagnosis of HCC in cirrhotic patients was $0,8291$ ( $p<0.05)$, AFP cut-off threshold $\geq 10,9 \mathrm{ng} /$ $\mathrm{ml}$ was highest for diagnosing $\mathrm{HCC}$ in cirrhotic patients with the sensitivity of $80,43 \%$ and the specificity $75,86 \%$. Conclusion: Serum AFP level is a simple test of high sensitivity and specificity in screening for HCC complications in cirrhotic patients.

Keywords: AFP, HCC, cirrhosis

\section{I. ĐĂT VẤN ĐỀ}

Xơ gan là giai đoạn cuối của một quá trình viêm hoại tử tế bào gan xen lẫn với sự phát triển tổ chức xơ và sự tái tạo các tế bào gan để bù trừ

\footnotetext{
${ }^{1}$ Đại học Y Dược Thành phố Hồ Chí Minh Bệnh viện Chợ Rẫy, Thành phố Hồ Chí Minh Chịu trách nhiệm chính: Võ Duy Thông Email: duythong@ump.edu.vn Ngày nhận bài: 13.11 .2020 Ngày phản biện khoa học: 31.12.2020 Ngày duyệt bài: 12.01.2021
}

\section{Võ Duy Thông ${ }^{1,2}$, Mai Hoài Sang1}

kéo dài. Xơ gan dù là nguyên nhân nào cũng có nguy cơ cao biến chứng thành ung thư gan nguyên phát [1]. Theo nghiên cứu của Coskun [2], tỉ lệ HCC ở bệnh nhân xơ gan trong khoảng 2-6,6\%. Ung thư biểu mô tế bào gan (HCC) được biết là dạng phổ biến nhất của ung thư gan nguyên phát [3], là nguyên nhân gây tử vong do ung thư cao thứ tư trên thế giới với khoảng 780,000 người mỗi năm, với tî lệ mắc khoảng 9,5/10,000 người/năm. Tại Việt Nam, theo thống kê của IARC (International Agency for Research on Cancer) năm 2008, ung thư gan đứng hàng đầu trong tất cả các bệnh ung thư thường gặp ở cả hai giới. Nguyên nhân là do tình trạng nhiễm viêm gan vi rút $B$ (HBV) trong dân số rất phổ biến (15 - 20\%) [4]. Mặc dù có nhiều chiến lược phòng ngừa toàn câu như chích ngừa $\mathrm{HBV}$ nhưng hiện tại tỉ lể mắc $\mathrm{HCC}$ ở những nước phát triển và đang phát triển vẫn đang tăng gây tổn hại nhiều về con người và chi phí điều trị [5].

Alpha-fetoprotein (AFP) có lẽ là chất chỉ điểm khối u được xác định tốt nhất cho HCC. Do vậy, AFP được sử dụng rộng rãi trong các cơ sở lẩm sàng như một công cụ chẩn đoán và tiên lượng hổ trợ. Có tới $70 \%$ các trường hợp HCC có nồng độ AFP trong huyết thanh tăng cao. Nhằm xác định ngưỡng chẩn đoán của AFP ở bệnh nhân xơ gan có HCC chúng tôi tiến hành nghiên cứu đề tài "Khảo sát giá trị AFP huyết thanh ở bệnh nhân xơ gan có ung thư biểu mô tế bào gan".

\section{II. ĐỐI TƯỢNG VÀ PHƯƠNG PHÁP NGHIÊN CỨU}

Thiết kế nghiên cứu: Mô tả cắt ngang tiến cứu và hồi cứu

Đối tượng nghiên cứu:

Tiêu chuẩn chọn bệnh

- Tuổi đủ 18 trở lên

- Đã được chẩn đoán xơ gan

- Đã được chụp CT có cản quang nhiều thì và/ hoặc MRI có cản từ nhiều thì.

- Có kết quả xét nghiệm định lượng nồng độ AFP.

Tiêu chuẩn loại trừ: Đã được chẩn đoán bất kỳ bệnh lý ác tính nào khác ngoài HCC, phụ nữ có thai.

Cõ̃ mẫu: Tất cả bệnh nhân thỏa tiêu chuẩn chọn mẫu và không có tiêu chuẩn loại trừ.

Các bước tiến hành và phân tích số liệu: Chúng tôi tiến hành thu thập số liệu từ hồ sơ 
bệnh án ngoại trú tại phòng khám ung bướu gan mật và ghép gan, Bệnh viện Đại học Y Dược TP Hồ Chí Minh. Hồi cứu tất cả các bệnh nhân đến khám tại phòng khám ung bướu gan mật và ghép gan từ tháng 01/2018 đến 10/2020, thỏa tiêu chuẩn chọn bệnh, không vi pham tiêu chuẩn loại trừ. Ghi nhận các thông tin bằng bảng thu thập số liệu.

Phân tích số liệu bằng phần mềm Stata 14.0. Các mối liên hệ được kiểm định bằng phép kiểm t với $p<0,05$ được xem là có ý nghĩa thống kê.

Vấn đề y đức: Nghiên cứu đã thông qua hội đồng y đức trường Đại học Y Dược TP. Hồ Chí Minh.

\section{KẾT QUẢ NGHIÊN CỨU}

Đặc điểm dân số nghiên cứu. Trong thời gian nghiên cứu, chúng tôi thu nhập được 75 bệnh nhân đủ tiêu chuẩn và đưa vào nghiên cứu với tuổi trung bình là $61,9 \pm 10,9$. Có 47 $(37,3 \%)$ là bềnh nhân nam và $28(62,7 \%)$ là bệnh nhân nữ, với tỷ lệ nam/nữ là $1,68 / 1$. Kết quả nghiên cứu ở bệnh nhân xơ gan, HCC chiếm tỷ lệ cao là $61,3 \%$ và không có $\mathrm{HCC}$ là $28,7 \%$. Phân bố về tỷ lệ nguyên nhân gây xơ gan và phân độ Child-Pugh của nhóm nghiên cứu được thể hiện ở Bảng 1 . Nguyên nhân viêm gan vi rút $B$ và $C$ gây $x$ ơ gan vẫn chiếm tỷ lệ cao, lần lượt là $48,0 \%$ và $29,3 \%$. Tỷ lệ Child-Pugh $A$ là $70,7 \%$, chiếm tỷ lệ cao nhất.

Bảng 1. Đăc điệ̉m dân số nghiên cứu

\begin{tabular}{|c|c|}
\hline Đặc điểm & Tống (n = 75) \\
\hline Tuối (năm) & $61,9 \pm 10,9$ \\
\hline Giới tính [n (\%)] & \\
Nam & $47(37,3 \%)$ \\
Nữ & $28(62,7 \%)$ \\
\hline Có HCC & $46(61,3 \%)$ \\
Không HCC & $29(28,7 \%)$ \\
\hline Nguyên nhân & \\
HBV & $36(48,0 \%)$ \\
HCV & $22(29,3 \%)$ \\
NAFLD/NASH & $2(2,7 \%)$ \\
Rượu & $6(8,0 \%)$ \\
Khăc & $6(8,0 \%)$ \\
\hline Phân độ Child-Pugh & \\
A & $53(70,7 \%)$ \\
B & $17(22,7 \%)$ \\
C & $5(6,6 \%)$ \\
\hline
\end{tabular}

Đăc điểm AFP ở bênh nhân xơ gan có HCC và không có HCC. Trong nghiên cứu của chúng tôi, có sự khác biệt về nồng độ AFP ở nhóm có HCC so với nhóm không có HCC có ý nghĩa thống kê với $p<0,05$ (Bảng 2).
Bảng 2. Giá trị AFP ở bệnh nhân xơ gan có $H C C$ và không HCC

\begin{tabular}{|c|c|c|c|c|}
\hline Nhóm & $\begin{array}{c}\text { Trung } \\
\text { vi }\end{array}$ & $\begin{array}{l}\text { Nhỏ } \\
\text { nhất }\end{array}$ & $\begin{array}{l}\text { Lớn } \\
\text { nhất }\end{array}$ & $P<0,01$ \\
\hline $\begin{array}{c}\text { Không } \\
\text { HCC } \\
\text { (ng/ml) }\end{array}$ & 13,1 & 1,2 & 111,1 & $\begin{array}{c}\text { Mann } \\
\text { Whitney } \\
\text { test }=-\end{array}$ \\
\hline $\begin{array}{l}\text { Có HCC } \\
(\mathrm{ng} / \mathrm{ml})\end{array}$ & 4197,1 & 2,2 & 160250 & 4,78 \\
\hline
\end{tabular}

Trong nghiên cứu của chúng tối HCC ở thùy gan phải chiếm tỉ lệ cao nhất với $69,6 \%$. Không có mối liên quan giữa nồng độ AFP huyết thanh với kích thước khối u và số lượng u ở bệnh nhân xơ gan (Bảng 3).

Bảng 3. Vị trí, kích thước của HCC

\begin{tabular}{|c|c|c|c|c|}
\hline Vị trí & $\begin{array}{l}\text { Số } \\
\text { ca }\end{array}$ & $\begin{array}{c}\text { Tỉ lệ } \\
\% \%\end{array}$ & $\mathbf{r}$ & p \\
\hline Thùy gan trái & 7 & 15,2 & \multirow{3}{*}{$-0,04$} & \multirow{3}{*}{0,76} \\
\hline Thùy gan phải & 32 & 69,6 & & \\
\hline Cả 2 thùy & 7 & 15,2 & & \\
\hline \multicolumn{5}{|l|}{ Kích thước u } \\
\hline$\leq 2 \mathrm{~cm}$ & 13 & 28,3 & \multirow{4}{*}{0,2} & \multirow{4}{*}{0,09} \\
\hline $2-3 \mathrm{~cm}$ & 14 & 30,4 & & \\
\hline $3-5 \mathrm{~cm}$ & 13 & 28,3 & & \\
\hline$\geq 5 \mathrm{~cm}$ & 6 & 13,0 & & \\
\hline
\end{tabular}

Trong nghiên cứu của chúng tối HCC ở thùy gan phải chiếm tỉ lệ cao nhất với $69,6 \%$. Không có mối liên quan giữa nồng độ AFP huyết thanh với kích thước khối u và số lượng u ở bệnh nhân xơ gan. Kết quả nghiên cứu cho thây, tỉ lệ u đơn độc chiếm tỉ lệ cao nhất với 78,3\%.

Giá trị của AFP trong chẩn đoán HCC ở bệnh nhân xơ gan. Khi khảo sát giá trị của AFP để chẩn đoán $\mathrm{HCC}$, kêtt quả cho thấy diện tích dưới đường cong ROC của nồng độ AFP để chẩn đoán HCC ở bệnh nhân xơ gan là tốt với $A U C=$ 0.8291 với $p=0.047<0.05$ (Hình 1).

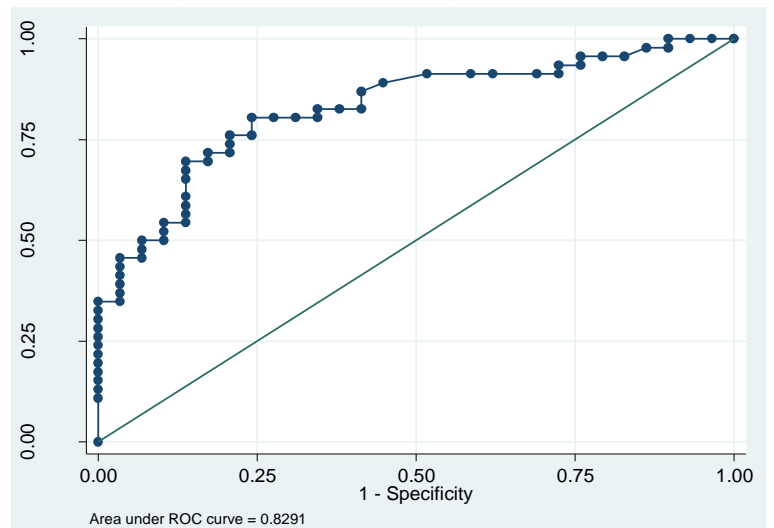

Hình 1. Đường cong ROC cho nồng độ AFP để chẩn đoán HCC ở bệnh nhân xơ gan 
Ngưỡng cắt tối ưu được xác định dựa trên hệ số J của Youden lớn nhất. Trong nghiên cứu của chúng tôi, ngưỡng cắt AFP $\geq 10,9 \mathrm{ng} / \mathrm{ml}$ có giá trị cao nhất để chẩn đoán HCC ở bệnh nhân xơ gan với độ nhạy là $80,43 \%$ và độ đặc hiệu là $75,86 \%$. Tại ngưỡng $\geq 17,8 \mathrm{ng} / \mathrm{ml}$ thì độ nhạy là $69,57 \%$ và đô đặc hiệu là $86,21 \%$ (Bảng 4 ).

Bảng 4. Các giá trị ngướng chẩn đoán AFP

\begin{tabular}{|c|c|c|c|}
\hline $\begin{array}{c}\text { Ngưỡng chẩn } \\
\text { đoán AFP } \\
\text { (ng/ml) }\end{array}$ & $\begin{array}{c}\text { Độ } \\
\text { nhạy }\end{array}$ & $\begin{array}{c}\text { Độ đặc } \\
\text { hiệu }\end{array}$ & $\begin{array}{c}\text { Chỉ số } \\
\text { Youden }\end{array}$ \\
\hline$\geq 9,7$ & $80,43 \%$ & $68,97 \%$ & 0,494 \\
\hline$\geq 10,8$ & $80,43 \%$ & $72,41 \%$ & 0,528 \\
\hline$\geq 10,9$ & $80,43 \%$ & $75,86 \%$ & 0,563 \\
\hline$\geq 12,3$ & $76,09 \%$ & $75,86 \%$ & 0,520 \\
\hline$\geq 12,5$ & $73,91 \%$ & $79,31 \%$ & 0,532 \\
\hline$\geq 12,9$ & $71,74 \%$ & $79,31 \%$ & 0,511 \\
\hline$\geq 13,8$ & $71,74 \%$ & $82,76 \%$ & 0,545 \\
\hline$\geq 17,3$ & $69,57 \%$ & $82,76 \%$ & 0,523 \\
\hline$\geq 17,8$ & $69,57 \%$ & $86,21 \%$ & 0,558 \\
\hline$\geq 18,1$ & $67,39 \%$ & $86,21 \%$ & 0,536 \\
\hline$\geq 19,3$ & $65,22 \%$ & $86,21 \%$ & 0,514 \\
\hline
\end{tabular}

\section{BÀN LUÂN}

Nghiên cứu của chúng tôi tương tự như nghiên cứu của J. Best [6] với nữ chiếm tỉ lệ là $22,1 \%$ thấp hơn nam là $79,1 \%$. Điều này có thể giải thích là nam có nhiều yếu tố nguy cơ hơn như rượu bia, đặc biệt tỉ lệ này ở Việt Nam khá cao. Ngoài ra viêm gan vi rút $\mathrm{B}, \mathrm{C}$ là những tác nhân lây truyền qua đường tiêm chích (như ma túy), đường tình dục. Trong nghiên cứu của chúng tôi, tuổi trung bình là $61,9 \pm 10,9$, bệnh nhân trẻ nhất là 40 tuổi và già nhất là 88 tuổi. Nghiên cứu của chúng tôi tương tự như nghiên cứu của J.Best là $66,8 \pm 10,8$ [6]. Kết quả nghiên cứu cho thấy, nguyên nhân chiếm tỉ lệ gây xơ gan cao nhất là viêm gan vi rút $B$ với $48,0 \%$, và viêm gan vi rút $C$ là $29.3 \%$. Nghiên cứu của J.Best và cộng sự [6] cũng chỉ ra rằng viêm gan vi rút $B$, viêm gan vi rút $C$ và rượu là những nguyên nhân hàng đầu của xơ gan và ung thư gan với tỉ lệ lần lượt là $15,1 \% ; 22,3 \%$ và $2,7 \%$. Trong nghiển cứu của chúng tôi số bệnh nhân có HCC là 46 chiếm tỉ lệ $61,3 \%$ cao hơn nhóm không HCC là 29 chiếm tî lệ $28,7 \%$. Trong nghiên cứu của J.Best [6] thì tỉ lệ xơ gan ở bệnh nhân HCC là $86,7 \%$. Tỉ lệ HCC ở nhiều tài liệu và nghiên cứu như của Coskun và công sự [2] là khoảng 2-6,6\% thấp hơn nghiên cứu của chúng tôi. Điều này là do nghiên cứu của chúng tôi cao hơn vì đối tượng chính trong nghiên cứu của chúng tôi là những bệnh nhân HCC với nền xơ gan. Nghiên cứu của chúng tôi tương tự như nghiên cứu của J.Best và cộng sự với Child $\mathrm{A}$ cao nhất với $67.6 \%$, child $\mathrm{B}$ là $25.9 \%$. Điều này phù hợp vì Child $C$ mức độ nặng bệnh nhân thường nhập viện điều trị nội trú với tình trạng mất bù của gan hay do biến chứng nhiễm trùng. Nghiên cứu của J.Best cho thấy ở bênh nhân HCC có nồng độ AFP cao hơn ở nhóm bệnh nhân xơ gan đơn thuần không có $\mathrm{HCC}$ với giá trị lần lượt là $39,35 \pm 12329,26 \mathrm{ng} / \mathrm{ml}$ và $2,7 \pm 115,92 \mathrm{ng} / \mathrm{ml}$ sự khác biệt này có ý nghĩa thống kê với $\mathrm{p}<0,001$.

Trong nghiên cứu của chúng tôi, ngưỡng cắt AFP $\geq 10,9 \mathrm{ng} / \mathrm{ml}$ có giá trị cao nhất để chẩn đoán HCC ở bệnh nhân xơ gan với độ nhay là $80,43 \%$ và độ đặc hiệu là $75,86 \%$. Tại ngưỡng $\geq 17,8 \mathrm{ng} / \mathrm{ml}$ thì độ nhạy là $69,57 \%$ và đô đặc hiệu là $86,21 \%$. Nghiên cứu của J.Best [6] thì tại ngưỡng $\geq 10 \mathrm{ng} / \mathrm{ml}$ có độ nhạy là $68,8 \%$ và đô đặc hiệu là $88,1 \%$, tại ngưỡng $\geq 20 \mathrm{ng} / \mathrm{ml}$ có độ nhạy là $58,2 \%$ và độ đặc hiệu là $94,0 \%$.

\section{KẾT LUÂN}

Nồng độ AFP huyết thanh là xét nghiệm đơn giản và hổ trợ việc tiên lượng diễn tiến HCC. Với ngưỡng cắt $A F P \geq 10,9 \mathrm{ng} / \mathrm{ml}$ có độ nhạy và độ đặc hiệu cao trong tầm soát biến chứng HCC ở bệnh nhân xơ gan.

\section{TÀI LIÊU THAM KHẢO}

1. Hà Văn Mạo, Hoàng Kỷ, Phạm Hoàng Việt. Xơ gan và ung thư gan nguyên phát. Nhà xuất bản y hoc. 2006, 42-48

2. Coskun $M$. Hepatocellular Carcinoma in the Cirrhotic Liver: Evaluation Using Computed Tomography and Magnetic Resonance Imaging. Exp Clin Transplant 2017,15(2):99-107

3. Nguyễn Quang Tuấn, Nguyễn Sào Trung, Nguyển Văn Thắng, Trân Minh Thôn. Ung thư gan nguyên phát: Đặc điểm giải phẫu bệnh - Lâm sàng. Tạp chí y học thành phố Hồ Chí Minh 2005. 9(1): $65-70$

4. Vũ Văn Vũ, Võ Thị Xuân Hạnh, Maji Thị Bích Ngọc, Lê Ngọc Lan Thanh. Dịch tế học, lâm sàng và cận lầm sàng ung thư gan nguyên phát Khảo sát 107 trường hợp điều tri tai Bệnh viện Ung Bướu TPHCM 2009 -2010. Tạp chí y học thành phố Hồ Chí Minh 2010. 14 (4): 134-138.

5. Amoros $R$, King $R$, Toyoda $H$, Kumada $T$. A continuous-time hidden Markov model for cancer surveillance using serum biomarkers with application to hepatocellular carcinoma. Metron 2019. 77 (2): 87-94

6. Best J, Bilgi $H$, Heider $D$, Schotten $C$. The GALAD scoring algorithm based on AFP, AFP-L3, and DCP significantly improves detection of BCLC early stage hepatocellular carcinoma. Z Gastroenterol 2016. 54 (12): 153-159. 